Persian fowlers, like their Indian confrères, are adepts in the art of snaring, and it is curious to note that one of their devices for capturing a wild hawk at night by means of a lantern (p. 75) is, with slight variation, to be found in the "Book of St. Albans, r486." Similarly a recipe for a slow-moulting hawk (p. $\mathrm{I}_{5} \mathrm{I}$ ) is also prescribed in that famous work of Julyana Berners. To explain such unexpected coincidences would take us now too far afield.

A valuable feature in the present translation is the number of footnotes which Col. Phillott has supplied, to explain and illustrate the Persian writer's meaning, to reconcile apparent discrepancies, or to confirm his statements from his own experience. To English readers interested in the literature of falconry, these footnotes will prove very instructive. The illustrations which accompany the text are of two kinds-reproductions of Persian drawings of hawking scenes, and

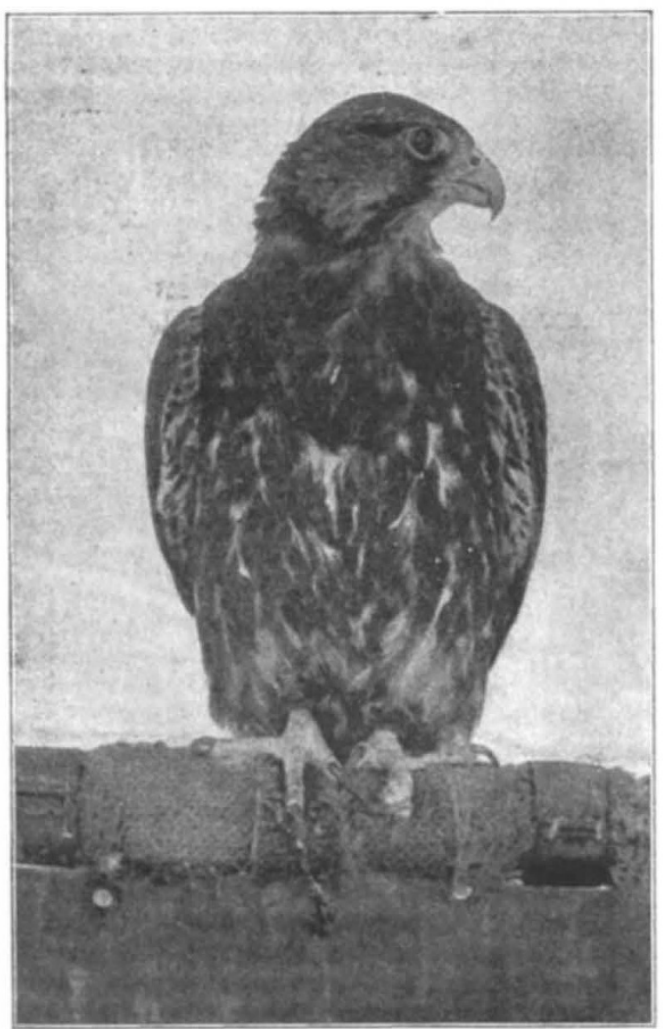

FIG. 2.-Young Passage Saker (Dark Variety). From "The Bãz-Nāma-yiNassiri: a Persian Treatise on Falconry."

photographs from life of hawks employed by Persian falconers. The reader is here presented with a sample of each.

J. E. H.

\section{DR. SVEN HEDIN ON CENTRAL ASIA.}

THE April number of the Geographical Journal contains two papers by Dr. Sven Hedin descriptive of his journeys through Tibet in 1906-8. The first of these is a narrative of his travels, which is necessarily so much abridged that it barely does more than give an idea of the extent and difficulties of his exploration; the other is a summary of the most important, or, rather, what Dr. Hedin regards as the most important, of his discoveries. The two are not necessarily identical, and it may be that when we have the full account of his travels the NO. 2065, VOL. 80] discoveries to which he now attaches greatest importance may prove of minor interest. For the present, however, we have only this summary, in which he enumerates the four most important results of his journey as the discovery of (I) the true source of the Brahmaputra, (2) the source of the Indus, (3) the "genetic" source of the Sutlej, and (4) the discovery of a continuous mountain chain, to which he applies the name Trans-Himalaya.

Of these the two first are of interest, especially the fact that no part of the drainage of the Kailas mountain finds its way into the Indus river; the third is a doubtful discovery, for though Dr. Hedin has discovered and visited the source of the largest of the feeders of the Manasarowar lake, it cannot in any proper sense of the word be regarded as belong ing any longer to the drainage area of the Sutlei river. At one time there was continuous flow from Manasarowar to Rakas Tul, and again from that to the Sutlej, but this latter has been dry for at least half a century, while the former seems to have become intermittent and likely to cease in the near future; except for a possible escape by underground percolation, no part of the water of these lakes now finds its way into the river, and even this supposititious communication would not justify us any longer in describing a tributary of either of the lakes as the source of the Sutlej, nor does the matter seem much bettered by the addition of the adjective genetic.

The most important, in his own view, of Dr. Hedin's discoveries, and the one around which controversy has settled, is that of a great continuous mountain range, coextensive with and parallel to the Himalayas, to which he has given the name TransHimalaya, a name to which exception has been taken, and which seems to require greater justification than Dr. Hedin has given. We may ignore the objection that the term was applied by Cunningham to the mountains lying between the Sutlej and the Indus, but we cannot accept the quotations from other authors cited as justification for the use of the term. A writer from the Indian side may use, with perfect correctness, the expression Trans-Himalayan, as applied to the country, or to explorations carried out, on the further side of the Himalayas, but it is a different matter when we are asked to accept the words as a definite geographical term, and once this proposal is brought forward the two questions arise as to whether the word is either justifiable in itself, or necessary. Of these two questions the first is a literary one, and it must be confessed that some real objections may be urged against the word adopted by Dr. Hedin, and accepted by Lord Curzon of Kedleston; but the second is the important one, for, unless the supposed range of mountains to which it is applied has a real individuality and independent existence, no special term is required or can be justified.

From earliest times it has been recognised that the great system of mountains which rises to the north of the Indo-Gangetic plain has an individuality of its own which deserves and requires a name, and the word Himalaya, originally applied to a part, has been extended to the whole chain of snowy peaks together with their dependent mountains of lower elevation. It has not, however, been so generally recognised that this unity belongs less to the mountains than to the plain at their foot, and some modern geographers, not content with merrely recognising the individuality of the great chain, have attempted to trace the individual ranges of which it is composed along the whole length of the system, and thereby have retarded a proper appreciation of the true nature of this system of mountains. A simile proves nothing, 
but is often useful as an illustration, and, without pressing the resemblance too far, the organisation of the Himalayan mountains may be compared to that of a great army, composed of many thousands of individual soldiers, grouped in regiments, these, again, in brigades and divisions, each having a separate individuality; but the individuality of the soldier differs from that of the regiment to which he belongs; this, again, merges in the individuality of the brigade, and the whole in that of the army. So with mountains, the peaks may be grouped into massifs, these into ranges, a series of which may form a great chain or system like that of the Himalayas or the Andes; but just as the brigades of an army are not each extended along the whole front, so the ranges do not extend along the whole length of the system. Each in turn comes to an end, and the chain is taken up by another, not as a direct continuation, but overlapping the end, so that the direction of the individual ranges is oblique to that of the system as a whole. Any other arrangement would probably be as physically impossible, with material such as that of which the earth's crust is composed, as the mar- of lofty, snow-clad peaks, misleading if meant as a name of a mountain range or system. Range it is not, for Dr. Hedin is clear enough on this point, as he repeatedly speaks of the separate ranges of which it is composed, and gives their number as no less than ten; mountain system it equally is not, having no separate existence. If a new name is required at all, it must be one which will unite these ranges with the Himalayas, not one which suggests a separation, for the valleys of the Sanpo and Indus no more separate the mountains on either side of them than, on a smaller scale, are the analogous valleys of the Rhone and the Rhine a reason for splitting up the unity of the Alps.

This criticism must not be taken as in any way a disparagement of Dr. Hedin's achievements; there can be but one opinion of the brilliance of his exploration and of the courage and determination with which he overcame the obstacles in his way. The publication of a detailed account of his travels will necessarily form an important addition to our knowledge of central Asia, but the fullest recognition of its importance does not involve an acceptance of Dr.

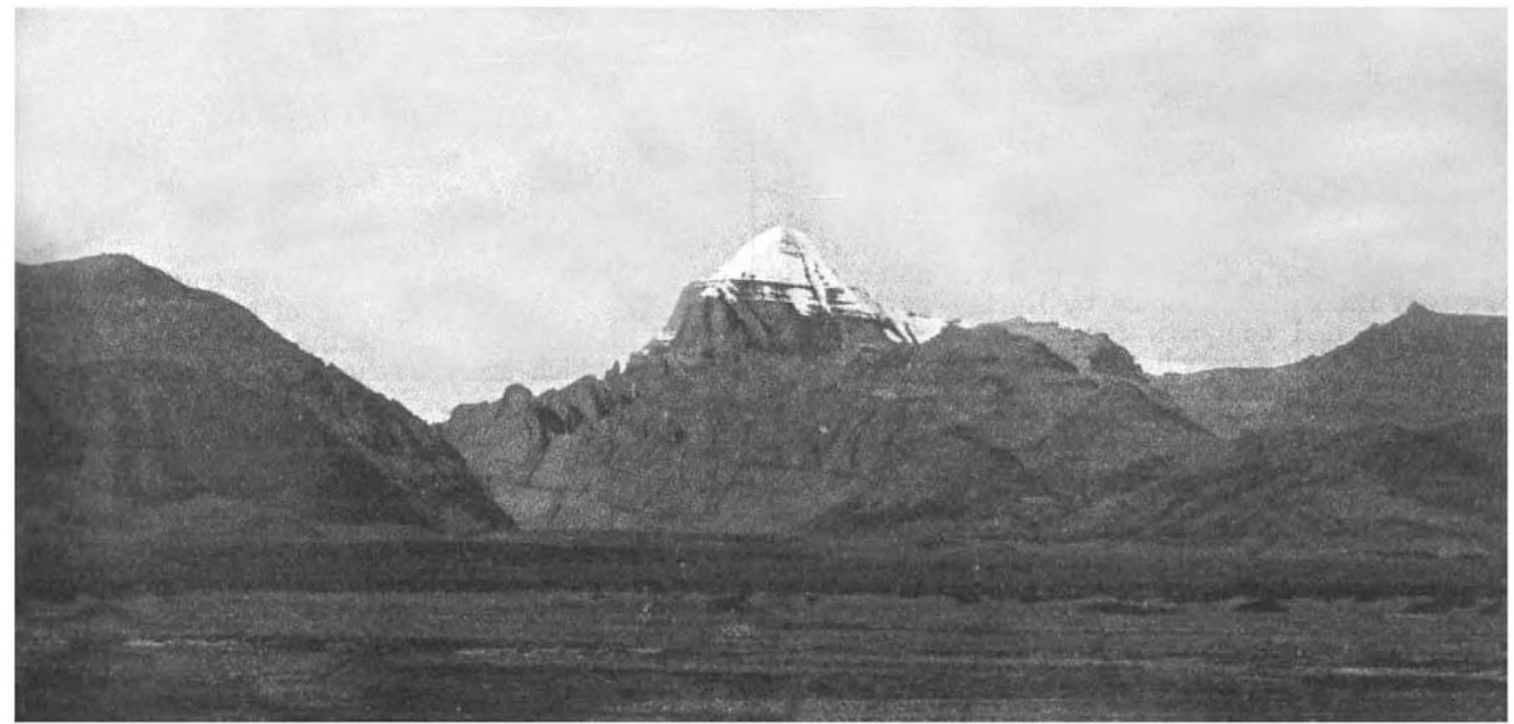

Kailas from the south-west From the Geographical Journal.

shalling of an army in brigades or divisions drawn up in lines extending along the whole length of the front would be militarily impracticable.

This interpretation of the orography of the Himalayas is borne out by such maps as we possess, and especially by those maps attached to Messrs. Burrard and Hayden's valuable sketch of the Himalayas, which exhibit the facts, rather than Colonel Burrard's interpretation. In these it will be seen that the high peaks of the Himalayas do not form a single range, but rather a band crossed obliquely by a series of ranges, and if we are to group these individual ranges into a single system, and to include in it the lesser ranges lying to the north and south, there is no reason, geographical or geological, for separating it from the mountains of southern Tibet and the northern territories of Cashmere. Structurally and orographically, the whole of the mountains between the Indian plains and the lake region of central Tibet belong to one great system, and the term which Dr. Hedin wishes to introduce is either unnecessary or misleading; needless if it merely indicates the country north of the first belt No. 2065 , VOL. 80$]$
Hedin's deductions, nor does a difference of opinion in regard to them imply any question of the accuracy of his observations.

\section{THE TEACHING OF GEOMETRY.}

$T \mathrm{HE}$ circular recently issued by the Board of Education on "The Teaching of Geometry and Graphic Algebra"' is an important document from at least two points of view. First, it has a very considerable educational value in indicating the successive steps or stages which it is proper for a teacher to take, and, secondly, it supplies information as to tine way in which the changes, introduced mainly by the Mathematical Association, have worked out. Those who have advocated the reformation of the teaching of geometry will be glad to know that the verdict of the Board of Education is favourable. "It should be stated at the outset that the general effect has been beneficial."

The reformers had most serious difficulties to face, the greatest, perhaps, being the almost divine authority 